\title{
summary
}

\section{Dental indices are higher in coronary heart disease patients but the difference is not significant}

Mattila KJ, Askainen S, Wolf J, Jousimies-Somer H, Valtonen V, Neiminen MS. Age, dental infections, and coronary heart disease. J Dent Res 2000; 79:756-760

Objective To evaluate the cardiovascular risk of periodontal disease in three groups of coronary heart disease (CHD) patients.

Design Case-controlled study in Finland.

Intervention Eighty-five people [24 with chronic CHD but no myocardial infarction (MI), 30 with chronic CHD and an MI history, and 31 with $\mathrm{CHD}$ and a recent $\mathrm{MI}$ ] with clinically or angiographicallyproved CHD were enrolled, along with 53 randomly selected controls matched for age, sex, socioeconomic status and locality. Structured patient history, blood tests for total cholesterol, high-density lipoprotein cholesterol and triglyceride were carried out. Clinical and radiographic dental examinations were made and four summary indices were constructed: CPSS (clinical periodontal sum score), CRSS (clinical and radiographic sum score), PTSS (panoramic tomography sum score) and RPPS (radiographic periapical and periodontal score). Logistic regression analysis was carried out on the data.

Results The dental indices, whether unadjusted or adjusted for smoking, lipids, age, number of teeth, gender, hypertension or socioeconomic status, did not significantly correlate with CHD.

\begin{tabular}{|c|c|c|c|c|}
\hline Index & Odds ratio & $\begin{array}{l}\text { adjusted } \\
95 \% \text { confidence } \\
\text { interval }\end{array}$ & Odds ratio & $\begin{array}{c}\text { Adjusted } \\
\text { 95\% confidence } \\
\text { interval }\end{array}$ \\
\hline CPSS & 0.98 & $0.87-1.15$ & 0.99 & $0.89-1.12$ \\
\hline CRSS & 1.02 & $0.89-1.15$ & 1.00 & $0.87-1.15$ \\
\hline PTSS & 0.93 & $0.67-1.28$ & 1.07 & $0.84-1.37$ \\
\hline RPPS & 1.04 & $0.85-1.27$ & 0.95 & $0.75-1.38$ \\
\hline
\end{tabular}

Conclusion Dental indices were higher in CHD patients than controls, but contrary to previous studies the differences were not significant.

Study supported by Paavo Nurmi Foundation, Finland.

Address for reprints: KJ Mattila, Department of Medicine, Division of Cardiology and Division of Infectious Diseases, Helsinki University Central Hospital, Haartmaninkatu, Finland. E-mail: kimmo.mattila@bayer.fi

\section{Commentary}

This well-designed case-control study is significant for two reasons. First, it is one of a group of recent studies (see Editorial in this issue) now indicating that periodontal disease is not significantly correlated with increased risk for CHD. Second, this study contradicts the seminal and previous study by the same group, which indicated that periodontal disease is a risk factor for CHD. ${ }^{1}$

One observation in particular is notable, however: the finding of an inverse correlation of CHD risk with age. That is, younger people ( $<50$ years) with periodontal disease have an increased relative risk of $\mathrm{CHD}$, compared with older people ( $>50$ years) who have periodontal disease. An age correlation was also observed by De Stefano et al. ${ }^{2}$ Interestingly, the age correlation identified in both the previous reports by Mattila et al and DeStefano et al was not found in the a new prospective cohort study by Hujoel and colleagues this year $^{3}$ (also reviewed in this issue).

What is one to make of the systole and diastole of this evidence? In terms of patient care, the data now indicate that it is inappropriate to plan periodontal care to prevent CHD. In terms of thought evolution, it reaffirms the need for lifelong learning.
1. Mattila $K$, Nieminen MS, Valtonen VV, Rasi VP, Kesaniemi YA, Syrjala SL, et al. Association between dental health and acute myocardial infarction. BMJ 1989; 298:779-781.

2. DeStefano F, Anda RF, Kahn HS, Williamson DF, Russell CM. Dental disease and risk of coronary heart disease and mortality. BMJ 1993; 306:688-691.

3. Hujoel $P$, Drangsholt $M$, Spiekerman $C$, DeRouen TA. Periodontal disease and coronary heart disease risk. JAMA 2000; 284:1406-1410.

Richard Niederman Office of Evidence-Based Dentistry, Harvard University and Forsyth Institute, Boston, Massachusetts, USA 